\title{
AP39, a Modulator of Mitochondrial and Oxidative Stress in Hypoxia-Exposed Trophoblasts
}

\section{Relevance for Preeclampsia Pathogenesis}

\author{
Ambart E. Covarrubias, ${ }^{* \dagger \neq}$ Edouard Lecarpentier, ${ }^{\star \S}$ Agnes Lo, ${ }^{*}$ Saira Salahuddin, ${ }^{\top}$ Kathryn J. Gray, S. Ananth Karumanchi, ${ }^{*}$ \\ and Zsuzsanna K. Zsengellér*
}

\begin{abstract}
From the Division of Nephrology, * Department of Medicine, and the Department of Obstetrics and Gynecology, "Beth Israel Deaconess Medical Center, Harvard Medical School, Boston, Massachusetts; the Faculty of Health Sciences, ${ }^{\dagger}$ University San Sebastian, Concepción, Chile; the Department of Medicine, ${ }^{\ddagger}$ Cedars-Sinai Medical Center, Los Angeles, California; the Faculty of Medicine of Créteil University Paris Est Créteil-Paris XII ${ }^{\S}$ and Department of Gynecology-Obstetrics and Reproductive Medicine, Centre Hospitalier Intercommunal de Créteil, Créteil, France; and the Division of Maternal-Fetal Medicine," Brigham and Women's Hospital, Boston, Massachusetts
\end{abstract}

Accepted for publication September 10, 2018.

Address correspondence to Zsuzsanna K. Zsengellér, M.D. Ph.D., Division of Nephrology, Department of Medicine, Beth Israel Deaconess Medical Center, 330 Brookline Ave/Sherman 163A, Boston, MA 02215. E-mail: zzsengel@ bidmc.harvard.edu.

\begin{abstract}
Although the cause of preeclampsia, a pregnancy complication with significant maternal and neonatal morbidity, has not been fully characterized, placental ischemia attributable to impaired spiral artery remodeling and abnormal secretion of antiangiogenic factors are thought to be important in the pathogenesis of the disease. Placental ischemia could impair trophoblast mitochondrial function and energy production, leading to the release of reactive oxygen species (ROS). ROS have been shown to stabilize hypoxia-inducible factor (HIF)- $1 \alpha$, which, in turn, may induce transcription of antiangiogenic factors, soluble fms-like tyrosine kinase 1 (sFLT1), and soluble endoglin in trophoblasts. Herein, we tested whether the angiogenic imbalance and oxidative stress in the preeclamptic placenta may be prevented by improving mitochondrial function. First, to evaluate the cause-effect relationship between mitochondrial function and sFLT1 production, a human trophoblast primary cell culture model was established in which hypoxia induced mitochondrial ROS production and concurrent sFLT1 increase. Second, treatment with AP39, a novel mitochondria-targeted hydrogen sulfide donor, prevented ROS production, reduced HIF- $1 \alpha$ protein levels, and diminished sFLT1 production. Finally, AP39, a modulator of mitochondrial bioenergetics enhanced cytochrome $c$ oxidase activity, reversed oxidative stress and antiangiogenic response in hypoxic trophoblasts. These results suggest that placental hypoxia induces ROS production, HIF- $1 \alpha$ stabilization, and SFLT1 up-regulation; these pathophysiological alterations can be attenuated by mitochondrial-targeted antioxidants. (Am J Pathol 2019, 189: 104-114; https:// doi.org/10.1016/j.ajpath.2018.09.007)
\end{abstract}

Preeclampsia (PE) is a relatively common pregnancy complication, characterized by hypertension and proteinuria occurring after 20 weeks of gestation. ${ }^{1}$ It is associated with significant maternal and neonatal morbidity and mortality. ${ }^{2}$ Although the cause and pathogenesis of PE have not been fully defined, placental ischemia attributable to impaired spiral artery remodeling and subsequent release of antiangiogenic factors are thought to be important in disease pathogenesis. ${ }^{3}$ Many groups have described the presence of reactive oxygen species (ROS) production, oxidative stress, and concurrent mitochondrial alterations in PE, likely a consequence of the abnormal placentation. $^{4-17}$ The activity of the mitochondrial electron

Supported by institutional support from the Beth Israel Deaconess Medical Center Departments of Medicine and Obstetrics and Gynecology.

Disclosures: S.A.K. is a coinventor on patents related to angiogenic biomarkers that are held by Beth Israel Deaconess Medical Center. S.A.K. has financial interest in Aggamin LLC, which is developing therapies for preeclampsia. 
transport chain enzyme cytochrome $c$ oxidase (COX) is reduced in the syncytiotrophoblast layer of the villi in preeclamptic placentas, implicating mitochondrial dysfunction in disease pathogenesis. ${ }^{18}$ Furthermore, an inverse correlation was found between mitochondrial function and soluble fms-like tyrosine kinase 1 (sFLT1), a key circulating antiangiogenic factor that contributes to the maternal syndrome of PE.

Oxidative stress can activate hypoxia-inducible transcription factors [eg, hypoxia-inducible factor (HIF)- $1 \alpha$, a heterodimeric transcription factor] that regulate expression of multiple genes within cells, ${ }^{19,20}$ including genes involved in angiogenesis. ${ }^{21,22}$ These genes include sFLT1, a circulating vascular endothelial growth factor signaling inhibitor; and soluble endoglin, a circulating transforming growth factor- $\beta$ inhibitor. ${ }^{23,24}$ sFLT1 inhibits the normal function of pregnancy-related angiogenic factors, including vascular endothelial growth factor and placental growth factor ${ }^{25-30}$; when released into the maternal circulation, it disrupts the maternal endothelium, leading to hypertension, proteinuria, and other systemic manifestations of PE. ${ }^{30-33}$

Although a role for oxidative stress in PE has been well established, clinical trials have shown that therapies with maternal vitamin $\mathrm{C}$ and vitamin $\mathrm{E}$ do not prevent PE. ${ }^{34,35}$ Therefore, there is interest in developing alternate strategies to reverse oxidative stress in the placenta. Mitochondrial-targeted antioxidants have been used in many models of ischemia-reperfusion injury ${ }^{36-38}$ and are an attractive alternative treatment because preeclamptic tissue is characterized by profound mitochondrial oxidative stress. The goal of the current study was to further characterize the role of mitochondrial oxidative stress in $\mathrm{PE}^{7,39-42}$ and to evaluate the therapeutic effect of a new mitochondrialtargeted hydrogen sulfide donor, AP39, that has been shown to reverse mitochondrial oxidative stress. ${ }^{43-47}$ AP39 is composed of a mitochondria-targeting motif, triphenyl phosphonium, coupled to a hydrogen sulfide-donating moiety (dithiolethione) by an aliphatic linker, which allows for direct hydrogen sulfide delivery to the mitochondria. The rationale of targeting the hydrogen sulfide directly into the mitochondria follows recent observations that mitochondrial hydrogen sulfide, at low concentrations, exerts antioxidant, cytoprotective, and stimulatory bioenergetic effects. ${ }^{45,48,49}$ We hypothesized that treatment with mitochondrial-targeted hydrogen sulfide using AP39 could ameliorate the oxidative mitochondrial damage observed in PE, leading to therapeutic effects. Herein, we demonstrate that AP39 exerts mitochondrial protective effects, leading to the prevention of an antiangiogenic response in hypoxia-exposed human primary trophoblasts.

\section{Materials and Methods}

\section{Materials}

AP39 (10-oxo-10-[4-(3-thioxo-3H-1,2-dithiol-5yl)phenoxy] decyl triphenyl-phosphonium bromide) was obtained from
Cayman Chemical (Ann Arbor, MI). 7-Azido-4methylcoumarin was obtained from Sigma-Aldrich (St. Louis, MO). MitoTracker Green FM and MitoSOX Red were from Thermo Fisher Scientific (Waltham, MA).

\section{Cytotrophoblast Isolation and Cell Culture Studies}

The Institutional Review Board at Beth Israel Deaconess Medical Center (Boston, MA) approved the collection and use of discarded human placentas. Third-trimester placentas were obtained immediately after planned cesarean section from mothers with uncomplicated pregnancies. Human primary cytotrophoblasts were isolated by a previously described protocol. ${ }^{50-52}$ Cytotrophoblasts were diluted to a final density of $1 \times 10^{6}$ cells per mL of Dulbecco's modified Eagle's medium supplemented with $10 \%$ fetal bovine serum, $100 \mathrm{IU} / \mathrm{mL}$ penicillin, $100 \mu \mathrm{g} / \mathrm{mL}$ streptomycin, and $2 \mathrm{mmol} / \mathrm{L}$ GlutaMax (Thermo Fisher Scientific, Asheville, NC). Cells were plated in 6-well tissue culture plates and incubated at $37^{\circ} \mathrm{C}$ in $95 \%$ air and a $5 \% \mathrm{CO}_{2}$ humidified atmosphere. After 2 hours, the medium was removed and the cells were gently washed with $1 \times$ phosphate-buffered saline (PBS) to remove excess cells. Fresh medium was then added, and the cells were incubated overnight.

After 24 hours, the cultured cytotrophoblasts were washed with PBS and pretreated with AP39 $(50,25$, or 10 $\mu \mathrm{mol} / \mathrm{L}$ ) for 30 minutes before hypoxia exposure. The cells were prepared in two sets of culture dishes, one for cell culture in ambient oxygen conditions and the other for cell culture in reduced oxygen conditions $\left(5 \% \mathrm{O}_{2}\right)$ at $37^{\circ} \mathrm{C}$. The oxygen concentration was regulated in a BioLabo Multigas Incubator (Juji Field Inc., Tokyo, Japan) for 18 hours. At the end of the experiments, the culture supernatants were collected and stored at $-20^{\circ} \mathrm{C}$ until assayed.

\section{Cell Viability/Cytotoxicity Measurements}

Cell Counting Kit-8 is a sensitive colorimetric assay for the detection of cell viability in cell proliferation and cytotoxicity assays. Dojindo's highly water-soluble tetrazolium salt, WST-8, is reduced by dehydrogenase activities in cells to give a yellow color formazan dye, which is soluble in the tissue culture medium. The amount of the formazan dye generated by the activity of dehydrogenases in cells is directly proportional to the number of living cells.

\section{Biochemical Measurements}

Freshly isolated human primary trophoblasts were seeded in 12-well plates (Nalge Nunc International, Penfield, NY) and incubated at $37^{\circ} \mathrm{C}$ in a $10 \% \mathrm{CO}_{2}$ humidified incubator overnight. The next day, cells were subjected to hypoxia or normoxia for 18 hours, along with various concentrations of AP39. After 18 hours, the cells were loaded with MitoTracker Green FM (number M7514; Thermo Fisher Scientific, Asheville, NC) and MitoSOX Red (number 
M36008; Thermo Fisher Scientific, Waltham, MA) fluorogenic dyes at 25 and $5 \mathrm{nmol} / \mathrm{L}$ final concentrations, respectively, for 15 minutes. In another set of experiments, hydrogen sulfide-sensitive fluorescent dye, 7-azido-4methylcoumarin, was incorporated in a cell-based assay to detect hydrogen sulfide production. ${ }^{45,47}$ Cells were pretreated with 7-azido-4-methylcoumarin at a $10 \mu \mathrm{mol} / \mathrm{L}$ final concentration for 1 hour. Cells were washed three times with PBS, and the specific fluorescence of the various dyes was visualized and imaged using an inverted EVOS FL Imaging System (Thermo Fisher Scientific).

\section{Western Blot Analysis}

Primary trophoblasts were incubated in $10 \%$ fetal bovine serum/Dulbecco's modified Eagle's medium, and cells were stimulated with increasing doses of AP39, 30 minutes before hypoxia exposure. Cells were washed with cold PBS and lysed with cold radioimmunoprecipitation buffer containing protease inhibitors [4-(2-aminoethyl)benzenesulfonyl fluoride hydrochloride, aprotinin, bestatin, E-64, leupeptin, and pepstatin; number 78430; Thermo Fisher Scientific, Waltham, MA]. The lysates were centrifuged at $10,000 \times g$ for 10 minutes at $4^{\circ} \mathrm{C}$, and Western blot analyses were performed, as previously described ${ }^{53}$ using primary antibodies against HIF-1 $\alpha$ (number 14179; Cell Signaling Technology, Inc., Danvers, MA), actin (number 4970; Cell Signaling Technology, Inc.), and COX IV (number 4844; Cell Signaling Technology, Inc.). Densitometry was performed using ImageJ software version 1.52a (NIH, Bethesda, MD; http://imagej.nih.gov/ij).

\section{IHC and Morphometry}

Human placental tissue for histology and immunohistochemistry (IHC) was obtained from uncomplicated or preeclamptic pregnancies (Table 1). To ensure that placenta samples were representative of the whole tissue and to assess intraplacental variability, the recommendation from the Amsterdam Placental Workshop Group Consensus Statement: Sampling and Definitions of Placental Lesions was followed. ${ }^{54}$ Standard histologic sections taken for this study included two full-thickness sections of the placenta disc from normal-appearing areas and additional sections from grossly abnormal areas. Tissues were fixed in $10 \%$ formalin for routine processing and staining. For nitrotyrosine and sFLT1 IHC of human placentas, paraffin sections $(5 \mu \mathrm{m}$ thick) were cut and deparaffinized. Optimal staining was achieved with the heat-induced antigen retrieval method, using $10 \mathrm{mmol} / \mathrm{L}$ citric acid, $\mathrm{pH} 6.00$. Endogenous peroxidase was quenched with $3 \% \mathrm{H}_{2} \mathrm{O}_{2}$ in double-distilled water for 15 minutes. To block non-specific binding, slides were incubated at $37^{\circ} \mathrm{C}$ with $2.5 \%$ normal horse serum in PBS for 30 minutes. Rabbit polyclonal nitrotyrosine antibody (A-21285 IgG2b; Thermo Fisher Scientific, Waltham, MA) was used at 1:500 overnight at $4^{\circ} \mathrm{C}$. Slides were then rinsed in PBS and developed using ImmPRESS HRP Anti-Rabbit IgG (Peroxidase) Polymer Detection Kit, per manufacturer's directions (Vector Laboratories, Burlingame, CA). Serial sections of human placenta were stained for human sFLT1 (1:200; AF231; R\&D Systems, Minneapolis, MN), as previously described. ${ }^{18}$ Sections were counterstained with hematoxylin, dehydrated, and mounted in Permount (Thermo Fisher Scientific, Atlanta, GA). Sections with no primary antibody were used as negative control slides. For positive controls, tissues previously shown to express the antigen of interest by IHC were used. ${ }^{18,55}$ As negative control for nitrotyrosine IHC, the FLEX Universal Negative Control, Rabbit, Ready-to-Use (Link), Unconjugated Antibody (number IR600; Agilent, Santa Clara, CA) was used; and for sFLT1 IHC, a Goat IgG Isotype Control (number 02-6202; Thermo Fisher Scientific, Waltham, MA) was used (Supplemental Figure S1).

Alternatively, fresh placental tissues were embedded in OCT compound (Thermo Fisher Scientific, Waltham, MA) and snap frozen in liquid nitrogen for immunofluorescence. Cryosections ( $5 \mu \mathrm{m}$ thick) of placental tissue were cut and equilibrated in PBS for 10 minutes at $37^{\circ} \mathrm{C}$, followed by incubation with $5 \mathrm{nmol} / \mathrm{L}$ MitoSOX Red for 15 minutes at $37^{\circ} \mathrm{C}$. Slides were then rinsed with PBS and mounted.

Morphometric measurements were generated from fluorescence microscopy images for MitoSOX Red and MitoTracker Green FM and from light microscopy images for trophoblast COX EHC, as well as for placental tissue nitrotyrosine and sFLT1 immunostaining, with an original

Table 1 Summary of the Characteristics

\begin{tabular}{|c|c|c|c|c|}
\hline Characteristic & $\begin{array}{l}\text { Control }(n=7), \\
\text { Mean } \pm \text { SEM }\end{array}$ & Range & $\begin{array}{l}\text { Preeclampsia }(n=7) \\
\text { Mean } \pm \text { SEM }\end{array}$ & Range \\
\hline Maternal age, years & $30.57 \pm 2.78$ & $18-36$ & $30.9 \pm 2$ & $26-40$ \\
\hline Gravity & $1.57 \pm 0.3$ & $1-3$ & $1.71 \pm 0.57$ & $1-5$ \\
\hline Parity & $0.28 \pm 0.18$ & $0-1$ & $0.43 \pm .029$ & $0-2$ \\
\hline Birth weight, grams & $2852 \pm 393$ & $1585-3845$ & $1375 \pm 181^{*}$ & $520-2020$ \\
\hline
\end{tabular}

${ }^{*} P<0.05$. 



Figure 1 Increased levels of nitrotyrosine, mitochondrial-derived superoxide generation, and sFLT1 expression in placentas of human preeclampsia cases. Immunohistochemical assay for nitrotyrosine (immunoreactivity: brown precipitate; $\mathbf{A}$ and $\mathbf{D})$, immunofluorescence assay for MitoSOX Red (superoxide production; red fluorescence; $\mathbf{B}$ and $\mathbf{E}$ ), and sFLT1 immunohistochemistry ( $\mathbf{C}$ and $\mathbf{F}$ ) were performed in placental tissues (gestationally age matched, near term), from normal pregnancies (NPs; $\mathbf{A}-\mathrm{C}$ ) and preeclampsia (PE) pregnancies (D-F). Quantitation for nitrotyrosine immunoreactivity (G), MitoSOX Red immunofluorescence (H), and SFLT1 immunoreactivity (I) in placentas from normal and preeclamptic pregnancy. OD per area (pixels ${ }^{2}$ ) of tissue was calculated in four high-power fields per sample. $n=7(\mathbf{A}-\mathbf{I}) .{ }^{* * *} P<0.001$ by $U$-test. Scale bar $=50 \mu \mathrm{m}(\mathbf{A}-\mathbf{F})$.

magnification of $\times 40$. Representative digital images of placental tissue or cell culture ( $n=3$ to 4 per group) were acquired. Four images were obtained and quantified per sample as replicates. Morphometric measurements were performed using ImageJ software version 1.47. To determine staining intensity, the threshold was set to include the MitoSOX Red fluorescence product or $3,3^{\prime}$-diaminobenzidine staining, and the mean intensity (OD) of reaction product was calculated per image. The mean intensity was divided by tissue area to calculate positivity per area.

\section{Enzyme-Linked Immunosorbent Assay}

sFLT1 in culture medium was measured by enzyme-linked immunosorbent assay using the human vascular endothelial growth factor receptor 1 Quantikine kit (R\&D Systems), following manufacturer's instructions. This assay has an intra-assay $\mathrm{CV}$ of $2.6 \%$ to $3.8 \%$ and an interassay $\mathrm{CV}$ of $5.5 \%$ to $9.8 \%$.

\section{COX in Situ Enzyme Chemistry and Functional Electron Microscopy}

Fresh-frozen placental tissues were cryosectioned and fixed in $2.5 \%$ glutaraldehyde in $0.1 \mathrm{~mol} / \mathrm{L}$ sodium cacodylate buffer (Tousimis Research Corp., Rockville, MD) for 20 minutes. Sections were washed in several changes of 0.05 $\mathrm{mol} / \mathrm{L}$ PBS ( $\mathrm{pH}$ 7.4) for 1.5 hours. The sections were treated for COX enzyme chemistry, as described previously, ${ }^{56-60}$ then processed for EPON embedding (TED PELLA Inc., Redding, CA). Thin sections ( $0.5 \mu \mathrm{m}$ thick) were cut, then imaged with a JEOL 1011 Transmission Electron
Microscope (JEOL, Tokyo, Japan), a Hamamatsu Orca-HR Digital Camera (Hamamatsu, Hamamatsu City, Japan), and AMT6000 software (Advanced Microscopy Techniques, Woburn, MA).

\section{Statistical Analysis}

All results were expressed as the means \pm SEM. Statistical comparisons between groups were made with the nonparametric $U$-test or Kruskal-Wallis test, followed by Dunn's post hoc comparison using Prism software version 7.0 (GraphPad Software, San Diego, CA). Comparisons were considered significant at $P<0.05$.

\section{Results}

Compared with gestationally matched nonhypertensive control pregnancies (Figure 1, A-C, and Table 1), increased levels of sFLT1 and oxidative stress were observed with ROS and reactive nitrogen species (RNS) generation in placentas obtained from human PE patients (Figure 1, D-F). Increased nitrotyrosine production (Figure 1, A, D, and G), a footprint of peroxynitrite/RNS release in the syncytiotrophoblast layer in preeclamptic placental tissue, was first observed. Mitochondrial-derived superoxide production was similarly increased in PE (Figure 1, B, E, and $\mathrm{H}$ ), as detected by MitoSOX Red, a fluorogenic dye for highly selective detection of mitochondrial-derived superoxide. As reported previously, PE placentas were characterized by an increased antiangiogenic response with elevated sFLT1 protein expression in the syncytiotrophoblast (Figure 1, C, F, and I). In addition, there was a strong correlation between sFlt1 expression and oxidative/nitrative 



Figure 2 Functional electron microscopy reveals that COX activity is decreased in syncytiotrophoblasts, but maintained in cytotrophoblasts, in preeclampsia (PE) placentas. Functional electron microscopy imaging of human nonhypertensive control $(\mathbf{A}-\mathbf{C})$ and PE placentas (D-F). Blue arrows show mitochondria with decreased COX activity. $n=4$ (A-F). Scale bars: $1 \mu \mathrm{m}$ (A and C); $500 \mathrm{~nm}$ (B, E, and F); $2 \mu \mathrm{m}$ (D). BM, basement membrane; CT, cytotrophoblast; MV, microvilli; N, nucleus; SCT, syncytiotrophoblast layer. stress $\left(r^{2}=0.89\right.$, MitoSOX Red versus sFLT1; $r^{2}=0.92$, nitrotyrosine versus sFLT1).

To study the morphology and function of mitochondria in the trophoblasts, COX enzyme histochemistry, imaged by transmission electron microscopy (functional electron microscopy), was assessed to evaluate electron transport chain enzyme deficiency, as described previously. ${ }^{18}$ To analyze COX enzyme activity in syncytiotrophoblasts versus cytotrophoblasts, normal (Figure 2, A-C) and PE (Figure 2, $\mathrm{D}-\mathrm{F})$ placentas were imaged by functional electron microscopy. Figure 2, A-C, depict villous syncytiotrophoblast and cytotrophoblast from a control human placenta with preserved mitochondria and intense COX activity. This preparation does not have any osmium or uranyl-acetate treatment; thus, the only electron density results from COX enzymatic staining. Figure 2D shows low magnification of villous tissue, including the syncytium and cytotrophoblast, of a preeclamptic human placenta. COX activity is mostly decreased in the mitochondria of syncytiotrophoblasts (Figure 2F). Figure 2E shows a cytotrophoblast in which mitochondria have maintained COX activity. These data suggest that the mitochondrial dysfunction noted in PE occurs predominantly in the syncytiotrophoblast layer of the placental tissue. Additional images of COX electron microscopy (Supplemental Figure S2) substantiate the finding that intact, functional mitochondria can be seen in all the placental samples from nonhypertensive controls (Supplemental Figure S2, A-J), whereas significantly less intact mitochondria are noted in placental syncytiotrophoblast from PE (Supplemental Figure S2, K-T).

To determine the effects of hypoxia (low oxygen concentrations, mimicking the ischemic state in human PE) on trophoblast mitochondrial health and the angiogenic profile, primary trophoblast cell culture from normal placentas was subjected to 18 hours of hypoxia $\left(5 \% \mathrm{O}_{2}\right)$ (Figure 3). As expected, sFLT1 production was increased in culture media after hypoxia incubation, as assessed by enzyme-linked immunosorbent assay (Figure 3A). Mitochondrial-derived superoxide production (MitoSOX Red, red labeling) was also increased in trophoblasts after hypoxia exposure (5\% $\mathrm{O}_{2}$ ) (Figure 3, D-F), compared with normoxia-exposed cells $\left(21 \% \mathrm{O}_{2}\right)$ (Figure 3, B, C, and F). These data imply that PE-induced antiangiogenic response and ROS production, both characteristics of human PE, can be recapitulated in a cell culture system.

It was then evaluated whether treatment of primary trophoblasts with the mitochondrial-targeted hydrogen sulfide donor, AP39, restored mitochondrial health in cells exposed to hypoxic conditions $\left(5 \% \mathrm{O}_{2}\right)$. Compared with controls, AP39-treated cells exhibited increased active mitochondrial content, assayed by MitoTracker Green FM, green fluorescence (Figure 4, A-E). Similarly, AP39 treatment reversed the mitochondrial-derived superoxide production, assessed by MitoSOX Red immunofluorescence (Figure $4, \mathrm{~F}-\mathrm{J}$ ). To rule out the possibility that $21 \%$ may represent hyperoxia, as suggested by Tuuli et $\mathrm{al}^{61}$ and Chen et $\mathrm{al},{ }^{62}$ trophoblast culture studies were repeated under $8 \%$ $\mathrm{O}_{2}$ concentration. Although a modest increase was seen in sFLT1 at $8 \%$ compared with $21 \%$, the pattern of sFLT1 response to AP39 remained the same (Supplemental Figure S3).

Primary trophoblasts were then incubated for 18 hours in hypoxic conditions $\left(5 \% \mathrm{O}_{2}\right)$, and HIF- $1 \alpha$ transcription factor expression was assessed by Western blot analysis in the presence or absence of AP39 (Figure 5, A and B). Under hypoxic conditions, up-regulated HIF- $1 \alpha$ protein levels were reduced in a concentration-dependent manner by AP39 pretreatment (Figure 5, A and B). In these studies, AP39 pretreatment also significantly reduced downstream antiangiogenic factor, sFLT1, expression, as assessed by enzyme-linked immunosorbent assay (Figure 5C). At the 
A

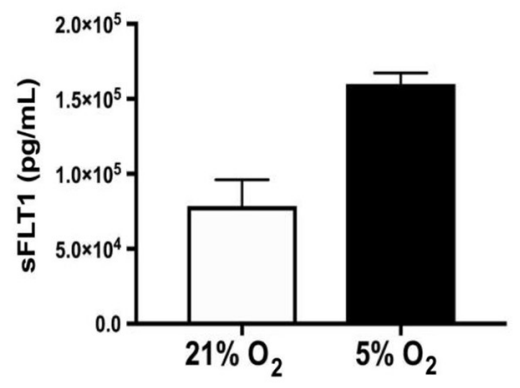

MitoSOX Red

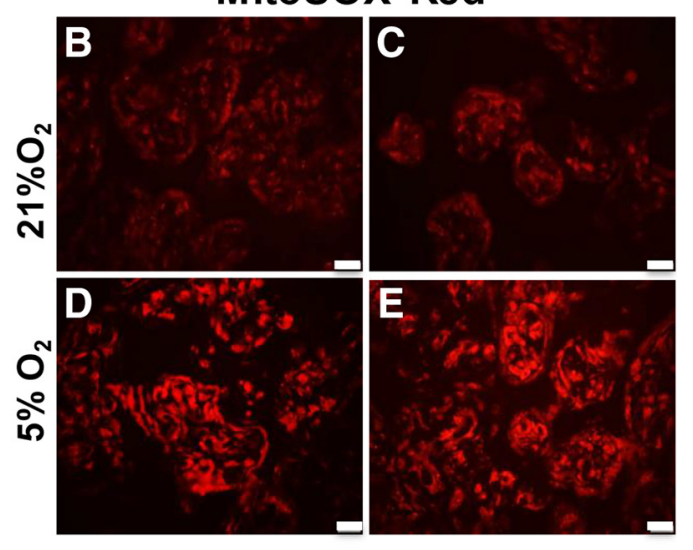

$\mathbf{F}$



Figure 3 Hypoxia exposure induces production of sFLT1 and mitochondrial-derived reactive oxygen species in human primary trophoblasts. sFLT1 enzyme-linked immunosorbent assay (A), immunofluorescence assay for MitoSOX Red (superoxide production, red fluorescence; $\mathbf{B}-\mathbf{E})$, and densitometry $(\mathbf{F})$ were performed in primary trophoblasts exposed to 18 hours of $5 \%$ hypoxia. ${ }^{*} P<0.05$ by $U$-test. Scale bar $=50 \mu \mathrm{m}(\mathbf{B}-\mathbf{E})$.

doses used to evaluate HIF- $1 \alpha$ and sFLT1, cell viability was maintained in all study groups (Figure 5D).

Cytochrome $c$ oxidase enzyme activity was significantly increased after $50 \mu \mathrm{mol} / \mathrm{L}$ AP39 pretreatment in both normoxic and hypoxic conditions in primary trophoblasts, as assessed by enzyme histochemistry (Figure 6, A and B). In addition, there was a trend for AP39 treatment to increase COX protein expression in a concentration-dependent manner (Figure 6, C and D), implicating that mitochondrial bioenergetics is preserved or even improved after treatment.

Finally, increased levels of 7-azido-4-methylcoumarin were seen in $50 \mu \mathrm{mol} / \mathrm{L}$ AP39-treated human primary trophoblast cells versus controls (Figure 7), indicating that, as expected, AP39 induced hydrogen sulfide release in these cells.

\section{Discussion}

Enhanced placental oxidative stress in PE is increasingly recognized to play a key pathophysiological role in PE. The origin of ROS and RNS and their by-products may be from mitochondria in preeclamptic placentas. ${ }^{5,40,42,63-73}$ Along these lines, in this study, it was demonstrated that placental oxidative stress partially initiates from mitochondria in human PE, and this state could be mimicked in vitro in a human primary trophoblast culture model. To prevent oxidative stress and the increased antiangiogenic response attributable to hypoxia, mitochondria-targeted hydrogen sulfide donor, AP39, was used, which released hydrogen sulfide in the mitochondria of trophoblasts and improved mitochondrial bioenergetics. The mitochondrial protective effect also resulted in overall cytoprotection, reduction of HIF- $1 \alpha$, and downstream sFLT1 release.

The beneficial properties of hydrogen sulfide in the mitochondria include the following: antioxidant effects, modulation of mitochondrial cell death pathways, and regulation of cellular bioenergetics. ${ }^{45,74-76}$ At lower concentrations, hydrogen sulfide serves as an alternative supporter of mitochondrial electron transport and ATP generation. ${ }^{48,77-79}$ Mitochondrial electron transport chain enzyme activity is decreased in syncytiotrophoblasts in preeclamptic placentas, suggesting that a mitochondrialtargeted antioxidant treatment could be beneficial for improving mitochondrial function in PE. ${ }^{18}$ Herein, AP39 treatment improved COX IV protein expression during exposure of trophoblasts to hypoxia. COX enzyme activity was also improved with AP39 pretreatment, which suggests that reduction of mitochondrial oxidative stress improved both COX IV levels and function. The biodynamics and biokinetics of AP39 have been previously published. ${ }^{73}$ AP39 contains three sulfur atoms and is, therefore, capable of increased hydrogen sulfide release up to 10 days after treatment. The high-potency and long-lasting effect elicited by this hydrogen sulfide donor strongly suggests that AP39 could be useful in many types of ischemic injury. AP39 has not been reported to have any major toxicity in various in vivo models tested; however, because AP39 would be expected to cross the placenta, further toxicologic studies in pregnant animals should be performed.

Our working hypothesis is that, in PE placentas, altered spiral artery remodeling generates a prolonged ischemic state, leading to mitochondrial damage and production of ROS and RNS in trophoblasts. This pro-oxidative state can lead to HIF- $1 \alpha$ transcription factor stabilization, which, in turn, promotes an antiangiogenic response ${ }^{80}$ and the systemic effects of PE. Herein, it was demonstrated that AP39 treatment can reverse mitochondrial stress, down-regulate HIF- $1 \alpha$, and decrease sFLT1 release. Kai et al ${ }^{81}$ also 

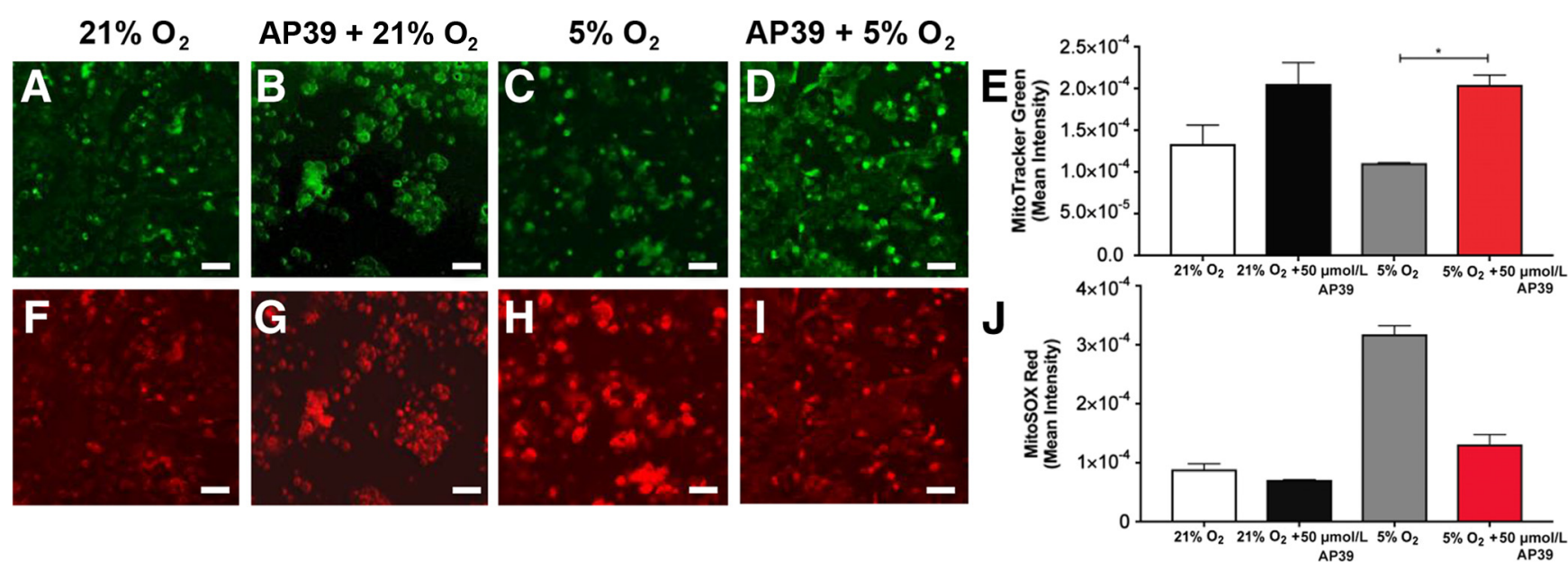

Figure 4 AP39 pretreatment reduces production of mitochondrial-derived reactive oxygen species and preserves active mitochondria in hypoxia-exposed primary trophoblasts. Immunofluorescence analysis of MitoTracker Green (active mitochondria; A-D) and MitoSOX Red (superoxide production; F-I) in primary trophoblasts treated with $50 \mu \mathrm{mol} / \mathrm{L}$ AP39 for 30 minutes, then exposed to 18 hours of $5 \%$ hypoxia. Quantitation of MitoTracker Green (E) and MitoSOX Red $(\mathrm{J})$ immunofluorescence in trophoblasts: OD per area $\left(\right.$ pixels $\left.^{2}\right)$ of cell surface area was calculated in four high-power fields per sample. $n=4$ per group (E and $\mathbf{J}) .{ }^{*} P<0.05$ by Kruskal Wallis test. Scale bar $=50 \mu \mathrm{m}(\mathbf{A}-\mathbf{D}$ and $\mathbf{F}-\mathbf{I})$.

reported that hydrogen sulfide donors have an inhibitory effect on HIF-1-dependent gene expression in cultured mouse hepatocytes and in vivo. The direct relationship between oxygen sensing and ROS generation was shown by Chandel et al, ${ }^{82}$ who demonstrated that COX exhibits intrinsic sensitivity to oxygen, allowing it to serve as an oxygen sensor. This group also has shown that HIF-1a protein stabilization was detected within 30 minutes at $1.5 \%$ $\mathrm{O}_{2}$ in hepatocytes, linking the mitochondrial enzyme COX to HIF- $1 \alpha$ activation. In other diseases, such as pulmonary arterial hypertension and cancer, mitochondrial abnormalities that disturb the ROS-HIF- $1 \alpha-\mathrm{Kv} 1.5$ oxygen-sensing pathway have been demonstrated to contribute to disease pathogenesis. $^{83}$ In this study, exposure of primary

A



C

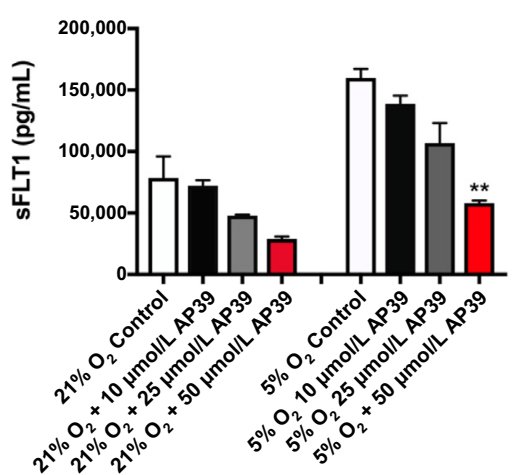

B

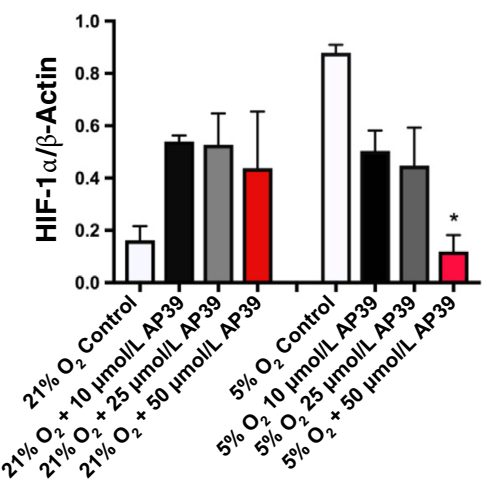

D



Figure 5 AP39 pretreatment reduces hypoxiainducible factor (HIF)- $1 \alpha$ and SFLT1 protein expression in hypoxia-exposed human primary trophoblasts and maintains cell viability. A: Representative Western blot analysis of HIF- $1 \alpha$ (one of three experiments) in primary trophoblasts pretreated with $\operatorname{AP} 39(10,25$, and 50 $\mu \mathrm{mol} / \mathrm{L})$ for 30 minutes, then exposed to normoxia $\left(21 \% 0_{2}\right)$ or 18 hours of $5 \%$ hypoxia. B: Summary densitometry of three HIF- $1 \alpha$ Western blot analyses. C: sFLT1 enzyme-linked immunosorbent assay in primary trophoblasts with same treatment as in A and B. D: Cell viability in primary trophoblasts assessed by Dojindo's Cell Counting Kit- 8 colorimetric assay. ${ }^{*} P<0.05$ compared with control; ${ }^{* *} P<0.01$ compared with control by Kruskal-Wallis test, followed by Dunn's multiple comparison post hoc test. 

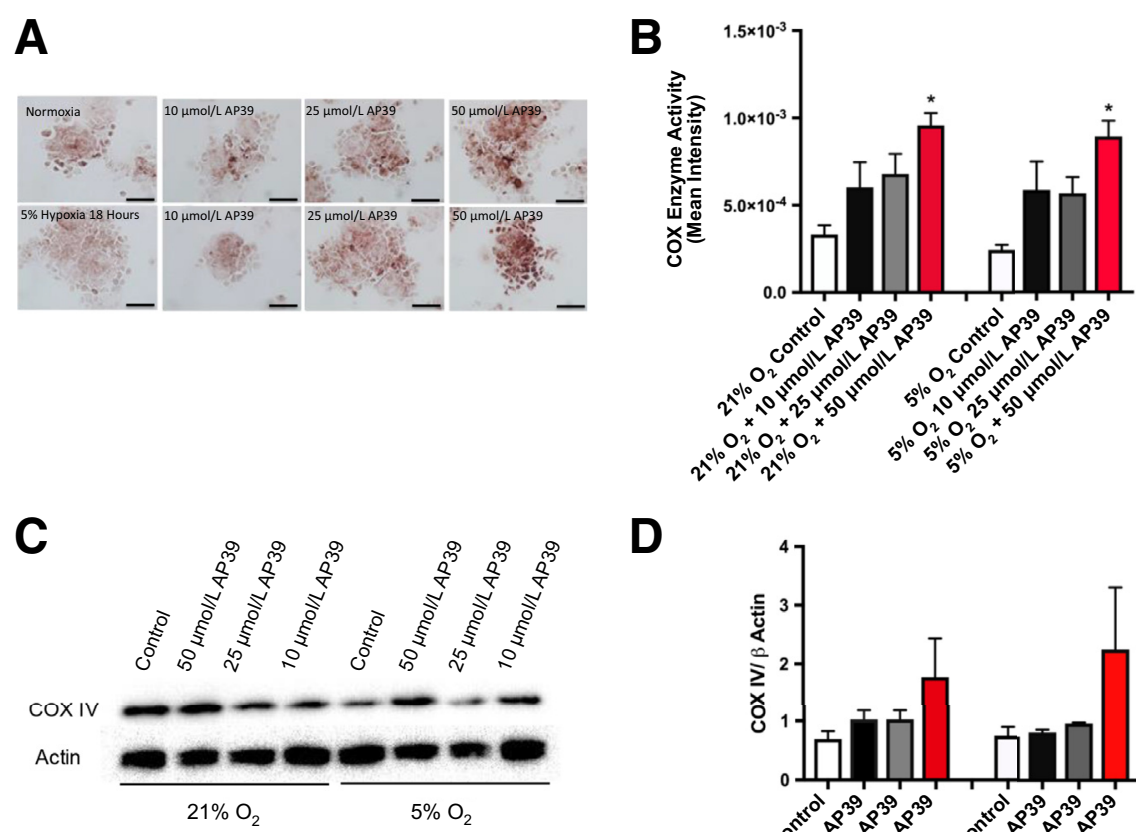

D



Figure 6 AP39 pretreatment induces mitochondrial COX IV activity and expression in hypoxia-exposed human primary trophoblasts. Representative COX enzyme histochemistry and summary data (A and B) and representative Western blot analysis of COX IV and summary data (C and $\mathbf{D})$ in primary trophoblasts pretreated with AP39 $(10,25$, and $50 \mu \mathrm{mol} / \mathrm{L})$ for 30 minutes, then exposed to normoxia or 18 hours of $5 \%$ hypoxia. Quantitation is shown. ${ }^{*} P<0.05$ compared with control by Kruskal Wallis test, followed by Dunn's multiple comparison post hoc test. Scale bar $=50 \mu \mathrm{m}(\mathbf{A})$. trophoblasts to hypoxia up-regulated HIF-1 $\alpha$. HIF-1 $\alpha$ up-regulation was inhibited by AP39, likely because of protection of the mitochondrial electron transport chain from oxidative stress, allowing preservation of COX activity and overall maintenance of mitochondrial bioenergetics.
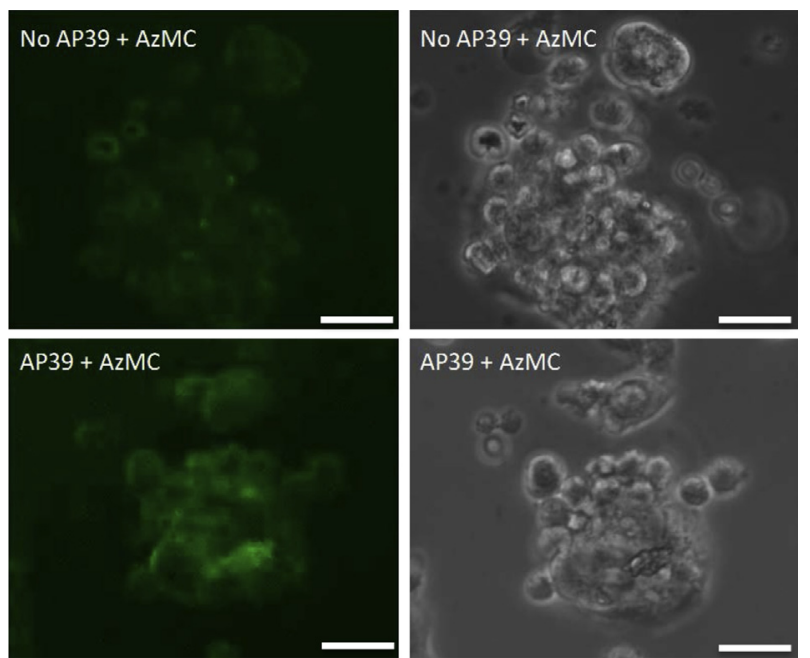

Figure 7 Hydrogen sulfide generation is detected in AP39-treated human primary trophoblast cells. Representative immunofluorescence assay for 7-azido-4-methylcoumarin (AzMC; green fluorescence; top and bottom left panels) and corresponding bright field images (top and bottom right panels) were performed in $50 \mu \mathrm{mol} / \mathrm{L} \mathrm{AP39-treated} \mathrm{(bottom}$ left and right panels) or nontreated (top left and right panels) human primary trophoblast cells. Scale bar $=25 \mu \mathrm{m}$.
Dysregulation of the hydrogen sulfide-producing enzyme, cystathionine $\gamma$-lyase, has been shown to contribute to maternal hypertension and placental abnormalities in preeclampsia. ${ }^{84,85}$ In addition, decreased levels of endogenous hydrogen sulfide have been reported in PE, ${ }^{86-88}$ suggesting that treatment with hydrogen sulfide may be of therapeutic utility. In support of this, in a hypertensive pregnant rat model, sodium hydrosulfide treatment has been shown to prevent hypertension and concomitantly reduce circulating plasma sFLT1 and vascular endothelial growth factor levels. ${ }^{89}$ This correlated with improved litter size with more viable fetuses. ${ }^{90}$

Hydrogen sulfide, at different concentrations, can have markedly different pharmacological effects (often described as a bell-shaped dose-response). For example, at low concentrations, hydrogen sulfide (and its pharmacologic donors) can increase mitochondrial electron transport by a variety of mechanisms (including direct electron donation, elevation of mitochondrial cAMP levels, direct activation of ATP synthase, and mitochondrial antioxidant effects). At higher concentrations, hydrogen sulfide starts to inhibit mitochondrial function through direct inhibition of mitochondrial complex IV. This function has been often cited in the context of on-demand metabolic inhibition (pharmacologic hibernation). In addition, hydrogen sulfide has been shown to alter (up-regulate or down-regulate) the expression of many different proteins in various cells and tissues. ${ }^{46}$ In the current study, the concentrations of AP39 used may have exerted beneficial effects via direct 
antioxidant effects (mitochondrial protection), as well by alterations in the activity and expression of complex IV, thereby modulating mitochondrial ROS production and downstream responses.

\section{Conclusions}

AP39 exerts its beneficial effects on trophoblast mitochondrial function by targeted delivery of hydrogen sulfide, which, at the concentrations tested, improves mitochondrial bioenergetics by acting as an alternative supporter of mitochondrial electron transport and ATP generation. The improved mitochondrial function prevents the release of ROS/RNS, leading to decreased HIF-1 $\alpha$ stabilization and attenuated expression of sFLT1. However, whether improvement of mitochondrial stress is sufficient to account for the beneficial effects of AP39 requires further testing in genetic models of mitochondrial disease. Additional studies are needed to demonstrate the relative beneficial effects of AP39 in trophoblasts versus endothelial cells and to determine whether targeting mitochondrial bioenergetics may ameliorate PE signs and symptoms in animal models of the disease.

\section{Supplemental Data}

Supplemental material for this article can be found at https://doi.org/10.1016/j.ajpath.2018.09.007.

\section{References}

1. American College of Obstetricians and Gynecologists, Task Force on Hypertension in Pregnancy: Hypertension in pregnancy: report of the American College of Obstetricians and Gynecologists' Task Force on Hypertension in Pregnancy. Obstet Gynecol 2013, 122: $1122-1131$

2. MacKay AP, Berg CJ, Atrash HK: Pregnancy-related mortality from preeclampsia and eclampsia. Obstet Gynecol 2001, 97:533-538

3. Redman CW, Sargent IL: Latest advances in understanding preeclampsia. Science 2005, 308:1592-1594

4. Walsh SW: Maternal-placental interactions of oxidative stress and antioxidants in preeclampsia. Semin Reprod Endocrinol 1998, 16: 93-104

5. Wang Y, Walsh SW: Placental mitochondria as a source of oxidative stress in pre-eclampsia. Placenta 1998, 19:581-586

6. Sikkema JM, van Rijn BB, Franx A, Bruinse HW, de Roos R, Stroes ES, van Faassen EE: Placental superoxide is increased in preeclampsia. Placenta 2001, 22:304-308

7. Muralimanoharan S, Maloyan A, Mele J, Guo C, Myatt LG, Myatt L: MIR-210 modulates mitochondrial respiration in placenta with preeclampsia. Placenta 2012, 33:816-823

8. Myatt L, Kossenjans W, Sahay R, Eis A, Brockman D: Oxidative stress causes vascular dysfunction in the placenta. J Matern Fetal Med 2000, 9:79-82

9. Myatt L, Cui X: Oxidative stress in the placenta. Histochem Cell Biol 2004, 122:369-382

10. Hubel CA: Oxidative stress in the pathogenesis of preeclampsia. Proc Soc Exp Biol Med 1999, 222:222-235
11. Raijmakers MT, Dechend R, Poston L: Oxidative stress and preeclampsia: rationale for antioxidant clinical trials. Hypertension 2004, 44:374-380

12. Raijmakers MT, Roes EM, Zusterzeel PL, Steegers EA, Peters WH: Thiol status and antioxidant capacity in womenwith a history of severe pre-eclampsia. BJOG 2004, 111: 207-212

13. Jauniaux E, Watson AL, Hempstock J, Bao YP, Skepper JN, Burton GJ: Onset of maternal arterial blood flow and placental oxidative stress: a possible factor in human early pregnancy failure. Am J Pathol 2000, 157:2111-2122

14. Burton GJ, Jauniaux E: Placental oxidative stress: from miscarriage to preeclampsia. J Soc Gynecol Investig 2004, 11:342-352

15. Many A, Hubel CA, Fisher SJ, Roberts JM, Zhou Y: Invasive cytotrophoblasts manifest evidence of oxidative stress in preeclampsia. Am J Pathol 2000, 156:321-331

16. Nezu M, Souma T, Yu L, Sekine H, Takahashi N, Wei AZ, Ito S, Fukamizu A, Zsengeller ZK, Nakamura T, Hozawa A, Karumanchi SA, Suzuki N, Yamamoto M: Nrf2 inactivation enhances placental angiogenesis in a preeclampsia mouse model and improves maternal and fetal outcomes. Sci Signal 2017, 10:pii: eaam5711

17. Burke SD, Zsengeller ZK, Khankin EV, Lo AS, Rajakumar A, DuPont JJ, McCurley A, Moss ME, Zhang D, Clark CD, Wang A, Seely EW, Kang PM, Stillman IE, Jaffe IZ, Karumanchi SA: Soluble fms-like tyrosine kinase 1 promotes angiotensin II sensitivity in preeclampsia. J Clin Invest 2016, 126:2561-2574

18. Zsengeller ZK, Rajakumar A, Hunter JT, Salahuddin S, Rana S, Stillman IE, Ananth Karumanchi S: Trophoblast mitochondrial function is impaired in preeclampsia and correlates negatively with the expression of soluble fms-like tyrosine kinase 1. Pregnancy Hypertens 2016, 6:313-319

19. Rajakumar A, Brandon HM, Daftary A, Ness R, Conrad KP: Evidence for the functional activity of hypoxia-inducible transcription factors overexpressed in preeclamptic placentae. Placenta 2004, 25: 763-769

20. Rajakumar A, Michael HM, Daftary A, Jeyabalan A, Gilmour C, Conrad KP: Proteasomal activity in placentas from women with preeclampsia and intrauterine growth restriction: implications for expression of HIF-alpha proteins. Placenta 2008, 29: 290-299

21. Furuya M, Kurasawa K, Nagahama K, Kawachi K, Nozawa A, Takahashi T, Aoki I: Disrupted balance of angiogenic and antiangiogenic signalings in preeclampsia. J Pregnancy 2011, 2011: 123717

22. Liu X, Deng Q, Luo X, Chen Y, Shan N, Qi H: Oxidative stressinduced Gadd45alpha inhibits trophoblast invasion and increases sFlt1/sEng secretions via p38 MAPK involving in the pathology of pre-eclampsia. J Matern Fetal Neonatal Med 2016, 29:3776-3785

23. Nagamatsu T, Fujii T, Kusumi M, Zou L, Yamashita T, Osuga Y, Momoeda M, Kozuma S, Taketani Y: Cytotrophoblasts up-regulate soluble fms-like tyrosine kinase-1 expression under reduced oxygen: an implication for the placental vascular development and the pathophysiology of preeclampsia. Endocrinology 2004, 145: 4838-4845

24. Yinon Y, Nevo O, Xu J, Many A, Rolfo A, Todros T, Post M, Caniggia I: Severe intrauterine growth restriction pregnancies have increased placental endoglin levels: hypoxic regulation viatransforming growth factor-beta 3. Am J Pathol 2008, 172:77-85

25. Venkatesha S, Toporsian M, Lam C, Hanai J, Mammoto T, Kim YM, Bdolah Y, Lim KH, Yuan HT, Libermann TA, Stillman IE, Roberts D, D'Amore PA, Epstein FH, Sellke FW, Romero R, Sukhatme VP, Letarte M, Karumanchi SA: Soluble endoglin contributes to the pathogenesis of preeclampsia. Nat Med 2006, 12: 642-649

26. Levine RJ, Maynard SE, Qian C, Lim KH, England LJ, Yu KF, Schisterman EF, Thadhani R, Sachs BP, Epstein FH, Sibai BM, 
Sukhatme VP, Karumanchi SA: Circulating angiogenic factors and the risk of preeclampsia. N Engl J Med 2004, 350:672-683

27. Levine RJ, Lam C, Qian C, Yu KF, Maynard SE, Sachs BP, Sibai BM, Epstein FH, Romero R, Thadhani R, Karumanchi SA, Group CS: Soluble endoglin and other circulating antiangiogenic factors in preeclampsia. N Engl J Med 2006, 355:992-1005

28. Noori M, Donald AE, Angelakopoulou A, Hingorani AD, Williams DJ: Prospective study of placental angiogenic factors and maternal vascular function before and after preeclampsia and gestational hypertension. Circulation 2010, 122:478-487

29. Tsatsaris V, Goffin F, Munaut C, Brichant JF, Pignon MR, Noel A, Schaaps JP, Cabrol D, Frankenne F, Foidart JM: Overexpression of the soluble vascular endothelial growth factor receptor in preeclamptic patients: pathophysiological consequences. J Clin Endocrinol Metab 2003, 88:5555-5563

30. Maynard SE, Min JY, Merchan J, Lim KH, Li J, Mondal S, Libermann TA, Morgan JP, Sellke FW, Stillman IE, Epstein FH, Sukhatme VP, Karumanchi SA: Excess placental soluble fms-like tyrosine kinase 1 (sFlt1) may contribute to endothelial dysfunction, hypertension, and proteinuria in preeclampsia. J Clin Invest 2003, 111:649-658

31. Chambers JC, Fusi L, Malik IS, Haskard DO, De Swiet M, Kooner JS: Association of maternal endothelial dysfunction with preeclampsia. JAMA 2001, 285:1607-1612

32. Germain AM, Romanik MC, Guerra I, Solari S, Reyes MS, Johnson RJ, Price K, Karumanchi SA, Valdes G: Endothelial dysfunction: a link among preeclampsia, recurrent pregnancy loss, and future cardiovascular events? Hypertension 2007, 49: 90-95

33. Yinon Y, Kingdom JC, Odutayo A, Moineddin R, Drewlo S, Lai V, Cherney DZ, Hladunewich MA: Vascular dysfunction in women with a history of preeclampsia and intrauterine growth restriction: insights into future vascular risk. Circulation 2010, 122:1846-1853

34. Roberts JM, Myatt L, Spong CY, Thom EA, Hauth JC, Leveno KJ, Pearson GD, Wapner RJ, Varner MW, Thorp JM Jr, Mercer BM, Peaceman AM, Ramin SM, Carpenter MW, Samuels P, Sciscione A, Harper M, Smith WJ, Saade G, Sorokin Y, Anderson GB; Eunice Kennedy Shriver National Institute of Child Health; Human Development Maternal-Fetal Medicine Units Network: Vitamins C and E to prevent complications of pregnancy-associated hypertension. N Engl J Med 2010, 362:1282-1291

35. Rumbold AR, Crowther CA, Haslam RR, Dekker GA, Robinson JS, Group AS: Vitamins $\mathrm{C}$ and $\mathrm{E}$ and the risks of preeclampsia and perinatal complications. N Engl J Med 2006, 354:1796-1806

36. Yamada Y, Nakamura K, Abe J, Hyodo M, Haga S, Ozaki M, Harashima H: Mitochondrial delivery of coenzyme Q10 via systemic administration using a MITO-Porter prevents ischemia/reperfusion injury in the mouse liver. J Control Release 2015, 213:86-95

37. Dare AJ, Logan A, Prime TA, Rogatti S, Goddard M, Bolton EM, Bradley JA, Pettigrew GJ, Murphy MP, Saeb-Parsy K: The mitochondria-targeted anti-oxidant MitoQ decreases ischemiareperfusion injury in a murine syngeneic heart transplant model. J Heart Lung Transplant 2015, 34:1471-1480

38. Szczepanek K, Xu A, Hu Y, Thompson J, He J, Larner AC, Salloum FN, Chen Q, Lesnefsky EJ: Cardioprotective function of mitochondrial-targeted and transcriptionally inactive STAT3 against ischemia and reperfusion injury. Basic Res Cardiol 2015, 110:53

39. Maloyan A, Mele J, Muralimanohara B, Myatt L: Measurement of mitochondrial respiration in trophoblast culture. Placenta 2012, 33: 456-458

40. Myatt L, Muralimanoharan S, Maloyan A: Effect of preeclampsia on placental function: influence of sexual dimorphism, microRNA's and mitochondria. Adv Exp Med Biol 2014, 814: $133-146$

41. Vishnyakova PA, Volodina MA, Tarasova NV, Marey MV, Tsvirkun DV, Vavina OV, Khodzhaeva ZS, Kan NE, Menon R,
Vysokikh MY, Sukhikh GT: Mitochondrial role in adaptive response to stress conditions in preeclampsia. Sci Rep 2016, 6:32410

42. McCarthy CM, Kenny LC: Mitochondrial [dys]function: culprit in pre-eclampsia? Clin Sci (Lond) 2016, 130:1179-1184

43. Ahmad A, Szabo C: Both the H2S biosynthesis inhibitor aminooxyacetic acid and the mitochondrially targeted H2S donor AP39 exert protective effects in a mouse model of burn injury. Pharmacol Res 2016, 113:348-355

44. Ahmad A, Olah G, Szczesny B, Wood ME, Whiteman M, Szabo C: AP39, a mitochondrially targeted hydrogen sulfide donor, exerts protective effects in renal epithelial cells subjected to oxidative stress in vitro and in acute renal injury in vivo. Shock 2016, 45:88-97

45. Szczesny B, Modis K, Yanagi K, Coletta C, Le Trionnaire S, Perry A, Wood ME, Whiteman M, Szabo C: AP39, a novel mitochondriatargeted hydrogen sulfide donor, stimulates cellular bioenergetics, exerts cytoprotective effects and protects against the loss of mitochondrial DNA integrity in oxidatively stressed endothelial cells in vitro. Nitric Oxide 2014, 41:120-130

46. Szabo C, Papapetropoulos A: International Union of Basic and Clinical Pharmacology. CII: pharmacological modulation of H2S levels: H2S donors and H2S biosynthesis inhibitors. Pharmacol Rev 2017, 69:497-564

47. Le Trionnaire S, Perry A, Szczesny B, Szabo C, Winyard PG, Whatmore JL: The synthesis and functional evaluation of a mitochondria-targeted hydrogen sulfide donor, (10-oxo-10-(4-(3thioxo-3H-1, 2-dithiol-5-yl)phenoxy)decyl)triphenylphosphonium bromide (AP39). Med Chemistry 2014, 5:728-736

48. Szabo C, Ransy C, Modis K, Andriamihaja M, Murghes B, Coletta C, Olah G, Yanagi K, Bouillaud F: Regulation of mitochondrial bioenergetic function by hydrogen sulfide, part I: biochemical and physiological mechanisms. Br J Pharmacol 2014, 171:2099-2122

49. Modis K, Coletta C, Asimakopoulou A, Szczesny B, Chao C, Papapetropoulos A, Hellmich MR, Szabo C: Effect of S-adenosyl-Lmethionine (SAM), an allosteric activator of cystathionine-betasynthase (CBS) on colorectal cancer cell proliferation and bioenergetics in vitro. Nitric Oxide 2014, 41:146-156

50. Alsat E, Haziza J, Evain-Brion D: Increase in epidermal growth factor receptor and its messenger ribonucleic acid levels with differentiation of human trophoblast cells in culture. J Cell Physiol 1993, 154:122-128

51. Kliman HJ, Nestler JE, Sermasi E, Sanger JM, Strauss JF 3rd: Purification, characterization, and in vitro differentiation of cytotrophoblasts from human term placentae. Endocrinology 1986, 118: $1567-1582$

52. Rana S, Rajakumar A, Geahchan C, Salahuddin S, Cerdeira AS, Burke SD, George EM, Granger JP, Karumanchi SA: Ouabain inhibits placental sFlt1 production by repressing HSP27-dependent HIF-1alpha pathway. FASEB J 2014, 28:4324-4334

53. Rajakumar A, Cerdeira AS, Rana S, Zsengeller Z, Edmunds L, Jeyabalan A, Hubel CA, Stillman IE, Parikh SM, Karumanchi SA: Transcriptionally active syncytial aggregates in the maternal circulation may contribute to circulating soluble fms-like tyrosine kinase 1 in preeclampsia. Hypertension 2012, 59:256-264

54. Khong TY, Mooney EE, Ariel I, Balmus NC, Boyd TK, Brundler MA, Derricott H, Evans MJ, Faye-Petersen OM, Gillan JE, Heazell AE, Heller DS, Jacques SM, Keating S, Kelehan P, Maes A, McKay EM, Morgan TK, Nikkels PG, Parks WT, Redline RW, Scheimberg I, Schoots MH, Sebire NJ, Timmer A, Turowski G, van der Voorn JP, van Lijnschoten I, Gordijn SJ: Sampling and definitions of placental lesions: Amsterdam placental workshop group consensus statement. Arch Pathol Lab Med 2016, 140:698-713

55. Mukhopadhyay P, Horvath B, Zsengeller Z, Batkai S, Cao Z, Kechrid M, Holovac E, Erdelyi K, Tanchian G, Liaudet L, Stillman IE, Joseph J, Kalyanaraman B, Pacher P: Mitochondrial reactive oxygen species generation triggers inflammatory response and tissue injury associated with hepatic ischemia-reperfusion: therapeutic potential of mitochondrially targeted antioxidants. Adv Exp Med Biol 2012, 53:1123-1138 
56. Seligman AM, Karnovsky MJ, Wasserkrug HL, Hanker JS: Nondroplet ultrastructural demonstration of cytochrome oxidase activity with a polymerizing osmiophilic reagent, diaminobenzidine (DAB). J Cell Biol 1968, 38:1-14

57. Anderson WA, Bara G, Seligman AM: The ultrastructural localization of cytochrome oxidase via cytochrome. J Histochem Cytochem $1975,23: 13-20$

58. Bertoni-Freddari C, Fattoretti P, Casoli T, Di Stefano G, Solazzi M, Gracciotti N, Pompei P: Mapping of mitochondrial metabolic competence by cytochrome oxidase and succinic dehydrogenase cytochemistry. J Histochem Cytochem 2001, 49:1191-1192

59. Zsengeller ZK, Aljinovic N, Teot LA, Korson M, Rodig N, Sloan JL, Venditti CP, Berry GT, Rosen S: Methylmalonic acidemia: a megamitochondrial disorder affecting the kidney. Pediatr Nephrol 2014, 29:2139-2146

60. Zsengeller ZK, Ellezian L, Brown D, Horvath B, Mukhopadhyay P, Kalyanaraman B, Parikh SM, Karumanchi SA, Stillman IE, Pacher P: Cisplatin nephrotoxicity involves mitochondrial injury with impaired tubular mitochondrial enzyme activity. J Histochem Cytochem 2012, 60:521-529

61. Tuuli MG, Longtine MS, Nelson DM: Review: oxygen and trophoblast biology - a source of controversy. Placenta 2011, 32(Suppl 2): S109-S118

62. Chen B, Longtine MS, Nelson DM: Pericellular oxygen concentration of cultured primary human trophoblasts. Placenta 2013, 34:106-109

63. Vaka VR, McMaster KM, Cunningham MW Jr, Ibrahim T, Hazlewood R, Usry N, Cornelius DC, Amaral LM, LaMarca B: Role of mitochondrial dysfunction and reactive oxygen species in mediating hypertension in the reduced uterine perfusion pressure rat model of preeclampsia. Hypertension 2018, 72:703-711

64. Wang W, Wang R, Zhang Q, Mor G, Zhang H: Benzo(a)pyren-7,8dihydrodiol-9,10-epoxide induces human trophoblast Swan 71 cell dysfunctions due to cell apoptosis through disorder of mitochondrial fission/fusion. Environ Pollut 2018, 233:820-832

65. Ding GC, Chen M, Wang YX, Rui C, Xu W, Ding HJ, Shi ZH: MicroRNA-128a-induced apoptosis in HTR-8/SVneo trophoblast cells contributes to pre-eclampsia. Biomed Pharmacother 2016, 81:63-70

66. Costa MA, Fonseca BM, Teixeira NA, Correia-da-Silva G: The endocannabinoid anandamide induces apoptosis in cytotrophoblast cells: involvement of both mitochondrial and death receptor pathways. Placenta 2015, 36:69-76

67. Doridot L, Chatre L, Ducat A, Vilotte JL, Lombes A, Mehats C, Barbaux S, Calicchio R, Ricchetti M, Vaiman D: Nitroso-redox balance and mitochondrial homeostasis are regulated by STOX1, a preeclampsia-associated gene. Antioxid Redox Signal 2014, 21:819-834

68. Tang C, Liang J, Qian J, Jin L, Du M, Li M, Li D: Opposing role of JNK-p38 kinase and ERK1/2 in hydrogen peroxide-induced oxidative damage of human trophoblast-like JEG-3 cells. Int J Clin Exp Pathol 2014, 7:959-968

69. Daffu G, del Pozo CH, O'Shea KM, Ananthakrishnan R, Ramasamy R, Schmidt AM: Radical roles for RAGE in the pathogenesis of oxidative stress in cardiovascular diseases and beyond. Int J Mol Sci 2013, 14:19891-19910

70. Chapple SJ, Cheng X, Mann GE: Effects of 4-hydroxynonenal on vascular endothelial and smooth muscle cell redox signaling and function in health and disease. Redox Biol 2013, 1:319-331

71. Qian ZQ, Li XP, Wang CZ, He XY, Fang F: [Oxidative damage effect of the serum of severe preeclamptic patients on human umbilical vein endothelial cell] Chinese. Zhonghua Fu Chan Ke Za Zhi 2013, 48:193-197

72. Milczarek R, Hallmann A, Sokolowska E, Kaletha K, Klimek J: Melatonin enhances antioxidant action of alpha-tocopherol and ascorbate against NADPH- and iron-dependent lipid peroxidation in human placental mitochondria. J Pineal Res 2010, 49:149-155

73. Gero D, Torregrossa R, Perry A, Waters A, Le-Trionnaire S, Whatmore JL, Wood M, Whiteman M: The novel mitochondria- targeted hydrogen sulfide (H2S) donors AP123 and AP39 protect against hyperglycemic injury in microvascular endothelial cells in vitro. Pharmacol Res 2016, 113:186-198

74. Szabo C: Hydrogen sulphide and its therapeutic potential. Nat Rev Drug Discov 2007, 6:917-935

75. Szabo C, Papapetropoulos A: Hydrogen sulphide and angiogenesis: mechanisms and applications. Br J Pharmacol 2011, 164: $853-865$

76. Whiteman M, Le Trionnaire S, Chopra M, Fox B, Whatmore J: Emerging role of hydrogen sulfide in health and disease: critical appraisal of biomarkers and pharmacological tools. Clin Sci (Lond) 2011, 121:459-488

77. Goubern M, Andriamihaja M, Nubel T, Blachier F, Bouillaud F: Sulfide, the first inorganic substrate for human cells. FASEB J 2007, 21:1699-1706

78. Bouillaud F, Blachier F: Mitochondria and sulfide: a very old story of poisoning, feeding, and signaling? Antioxid Redox Signal 2011, 15: 379-391

79. Wang R: Physiological implications of hydrogen sulfide: a whiff exploration that blossomed. Physiol Rev 2012, 92:791-896

80. Karumanchi SA, Bdolah Y: Hypoxia and sFlt-1 in preeclampsia: the "chicken-and-egg" question. Endocrinology 2004, 145:4835-4837

81. Kai S, Tanaka T, Daijo H, Harada H, Kishimoto S, Suzuki K, Takabuchi S, Takenaga K, Fukuda K, Hirota K: Hydrogen sulfide inhibits hypoxia- but not anoxia-induced hypoxia-inducible factor 1 activation in a von hippel-lindau- and mitochondria-dependent manner. Antioxid Redox Signal 2012, 16:203-216

82. Chandel NS, McClintock DS, Feliciano CE, Wood TM, Melendez JA, Rodriguez AM, Schumacker PT: Reactive oxygen species generated at mitochondrial complex III stabilize hypoxiainducible factor-1alpha during hypoxia: a mechanism of $\mathrm{O} 2$ sensing. J Biol Chem 2000, 275:25130-25138

83. Archer SL, Gomberg-Maitland M, Maitland ML, Rich S, Garcia JG, Weir EK: Mitochondrial metabolism, redox signaling, and fusion: a mitochondria-ROS-HIF-1alpha-Kv1.5 O2-sensing pathway at the intersection of pulmonary hypertension and cancer. Am J Physiol Heart Circ Physiol 2008, 294:H570-H578

84. Wang K, Ahmad S, Cai M, Rennie J, Fujisawa T, Crispi F, Baily J, Miller MR, Cudmore M, Hadoke PW, Wang R, Gratacos E, Buhimschi IA, Buhimschi CS, Ahmed A: Dysregulation of hydrogen sulfide producing enzyme cystathionine gamma-lyase contributes to maternal hypertension and placental abnormalities in preeclampsia. Circulation 2013, 127:2514-2522

85. Holwerda KM, Weedon-Fekjaer MS, Staff AC, Nolte IM, van Goor H, Lely AT, Faas MM: The association of single nucleotide polymorphisms of the maternal cystathionine-beta-synthase gene with early-onset preeclampsia. Pregnancy Hypertens 2016, 6:60-65

86. Holwerda KM, Faas MM, van Goor H, Lely AT: Gasotransmitters: a solution for the therapeutic dilemma in preeclampsia? Hypertension 2013, 62:653-659

87. Holwerda KM, Karumanchi SA, Lely AT: Hydrogen sulfide: role in vascular physiology and pathology. Curr Opin Nephrol Hypertens 2015, 24:170-176

88. Ahmed A, Rezai H, Broadway-Stringer S: Evidence-based revised view of the pathophysiology of preeclampsia. Adv Exp Med Biol 2017, 956:355-374

89. Holwerda KM, Burke SD, Faas MM, Zsengeller Z, Stillman IE, Kang PM, van Goor H, McCurley A, Jaffe IZ, Karumanchi SA, Lely AT: Hydrogen sulfide attenuates sFlt1-induced hypertension and renal damage by upregulating vascular endothelial growth factor. J Am Soc Nephrol 2014, 25:717-725

90. Possomato-Vieira JS, Goncalves-Rizzi VH, Graca TU, Nascimento RA, Dias-Junior CA: Sodium hydrosulfide prevents hypertension and increases in vascular endothelial growth factor and soluble fms-like tyrosine kinase-1 in hypertensive pregnant rats. Naunyn Schmiedebergs Arch Pharmacol 2016, 389:1325-1332 